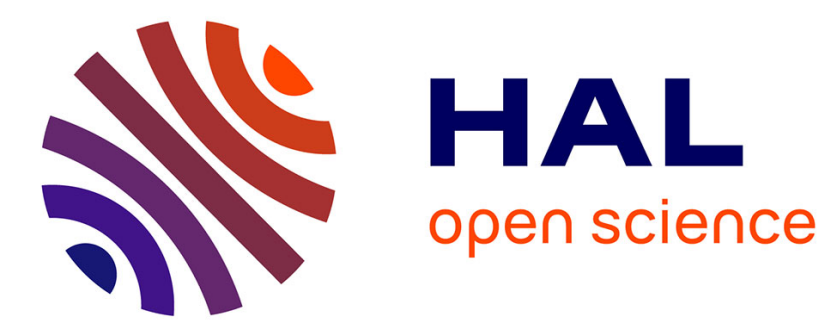

\title{
ON THE STRUCTURE AND BEHAVIOUR OF ECOSYSTEMS
}

\author{
J. Beddington, J. Lawton
}

\section{To cite this version:}

J. Beddington, J. Lawton. ON THE STRUCTURE AND BEHAVIOUR OF ECOSYSTEMS. Journal de Physique Colloques, 1978, 39 (C5), pp.C5-39-C5-43. 10.1051/jphyscol:1978515 . jpa-00217482

\section{HAL Id: jpa-00217482 https://hal.science/jpa-00217482}

Submitted on 1 Jan 1978

HAL is a multi-disciplinary open access archive for the deposit and dissemination of scientific research documents, whether they are published or not. The documents may come from teaching and research institutions in France or abroad, or from public or private research centers.
L'archive ouverte pluridisciplinaire HAL, est destinée au dépôt et à la diffusion de documents scientifiques de niveau recherche, publiés ou non, émanant des établissements d'enseignement et de recherche français ou étrangers, des laboratoires publics ou privés. 


\title{
ON THE STRUCTURE AND BEHAVIOUR OF ECOSYSTEMS
}

\author{
J. R. BEDDINGTON and J. H. LAWTON
}

Biology Department, University of York, York YO1 5DD. U.K.

\begin{abstract}
Résumé. -- Dans ce papier quelques-unes des questions centrales de l'écologie théorique sont considérées. Ce sont :

1) Quelles sont les conditions nécessaires et suffisantes pour la coexistence d'une collection d'espèces?

2) Quelles sont les relations entre la structure des chaînes alimentaires et leurs complexités et stabilités?

3) Est-ce que les écosystèmes possèdent un ensemble d'états stables ?

Les tentatives pour répondre à ces questions sont considérées en utilisant des modèles non linéaires, en même temps que leur évidence expérimentale.
\end{abstract}

Abstract. - In this paper some of the central questions of theoretical ecology are considered. They are :

1) What are the necessary and sufficient conditions for the coexistence of a collection of species ?

2) What are the relationships between the structure of food-webs and their complexity and stability ?

3) Do ecosystems have a variety of stable states ?

The attempts to answer these questions using non linear models are considered, together with the relevant empirical evidence.

In this paper we wish to consider the subset of theoretical ecology which is concerned with the way in which communities of plants and animals are able to persist and develop. A primary abstraction is the food-web, which may be thought of as the network which represents the energy flows between the component species of the ecosystem. The central questions with which we are concerned are :

a) What are the necessary and sufficient conditions for the coexistence of a collection of species ?

b) What are the relationships between the structure of food-webs and their complexity and stability ?

c) Do ecosystems have a variety of stable states?

To ask questions of this kind is to focus attention on the role of dynamic interactions between species (competition, predation and parasitism, and to a limited extent symbiosis) in structuring ecological communities [35]. However, it is pertinent to first enquire how good the empirical evidence is that interactions are important. We shall argue later that many communities (containing hundreds, or thousands of species) may well be composed of a large number of very loosely coupled, or effectively uncoupled independent systems. Neutral models [4] which ignore interactions might well provide extremely good descriptions of these large assemblages. Thus the community of several hundred species of anthropods which feed on mangrove (Rhizophora) appears to be mainly made up of independent species populations; interactions between them are not a major organising force [55].

Most so called community ecology, either theoretical or practical, is in fact concerned not with sets of hundreds or thousands of species, but with much smaller groups (ten species or less) for which there is little doubt that interactions are important [6], [10], [35]. This distinction is fundamental. The rules which determine the ways in which small sets, or guilds, of species behave may be quite different to the rules that determine the dynamic behaviour of much larger assemblages. Indeed it may be quite useless to study the former in an attempt to understand the latter. Nevertheless studies of the interactions between small groups of species, and the structure and dynamics of large assemblages overlap in a number of important ways. For example how do interactions between species determine the shapes of species - frequency distributions - the problem of the relative abundance of species [34] ? Or do whole communities saturate with species in evolutionary time? If they do, and the 
empirical evidence on this point is contradictory [10], [16], [56], [58], [67] what are the mechanisms ?

The preliminary list of questions which we posed are largely applicable to small sets of interacting species, because it is for these that we can obtain the most reliable experimental data, and make the greatest progress with analytical models. Next, we briefly review these models.

Traditionally the equations used to model ecosystems have been framed as sets of time independent non linear differential equations [26], [63]. A particular subset of the possible non linear models which has been the subject of considerable study is of this form

$$
\frac{\mathrm{d} X_{i}}{\mathrm{~d} t}=X_{i}\left(b_{i}-\sum_{j=0}^{n} \alpha_{i j} X_{j}\right) \text {. }
$$

The attractiveness of this model has much to do with its mathematical tractability rather than well founded confidence in its ability to mimic the interaction of a food-web. However the point has been made by Lotka [26] that it can be considered as an approximation to a more complex non linear model.

Of more immediate concern is the fact that time delays in feedback mechanisms are ubiquitous in ecological systems. Such time delays generated by age structures and delayed feedback in prey predator relationships have been the subject of considerable study [3], [28], [31], [45], [65]. Results indicate that there are fundamental quantitative differences between the behaviour of such systems and those framed as simple non delayed differential equations. Hence doubts have been expressed concerning any inferences that can be made from models that caricature reality in this way. One insight that indicates that some models may have somewhat wider applicability is that many delay equations, when formulated as integral equations, may be mimicked by extended series of differential equations [28], [62], [8].

Thus in the system :

$$
\dot{x}=F(z)
$$

with

$$
Z=\int_{-\infty}^{t} \psi(t-T) \times(T) \mathrm{d} T
$$

and using the form

$$
\Psi(t-T)=\frac{a^{P+1}}{P !}(t-T)^{P} \exp (-a(t-T))
$$

the original differential equation is supplemented by $P+1$ equations of the simple linear form

$$
\begin{gathered}
\dot{Z}=a\left(y_{1}-z\right) \\
\dot{y}_{1}=a\left(y_{2}-y_{1}\right) \\
\vdots \\
\dot{y}_{P}=a\left(x-y_{P}\right)
\end{gathered}
$$

where

$y_{i}=\frac{a^{P+1-i}}{(P-i) !} \int_{-\infty}^{t}(t-\tau)^{P-i} \exp -a(t-\tau) \times(\tau) \mathrm{d} \tau$.

By analysing generalized Lotka-Volterra models which ignore the complication of time-delays, for the existence of equilibria (with all populations positive - an important biological constraint : [51]), and considering the local stability of these equilibria in the standard manner [32] theoretical ecologists have tried to gain insights into the structure of natural communities.

A central assumption of these theoretical considerations is that the persistent, quasi-stable populations which we observe in real ecological communities demand parameter values in their model counterparts which lead to locally stable equilibria or to limit cycle behaviour. Combinations of parameter values which produce only negative population equilibria, or which lead to exponential growth or extinction following a small disturbance from a positive equilibrium, are obviously inappropriate and will not be observed in real communities. Encouragingly there is an increasing number of studies which show that the parameter values which characterise the interactions of real population systems are very far from being a haphazard selection of all numerically possible values [18], [50], [52], [64]; that certain field communities have converged in structure from different origins [5], [9], [20], [57]; that consistent stable configurations of species develop via extinctions from random mixtures of large pools [42]; and that equivalent parameters may evolve markedly on different community backgrounds [11], [44], [49]. First steps in the theoretical analysis of the evolution of stable combinations of parameter values have been made by Lawlor and Maynard Smith [21]. However, there are very few inequivocal experimental demonstrations that the parameter values and combinations which are observed in real communities lead to stable equilibria or cycles in their model counterparts, and that other, unencountered values and combinations do not. Indeed this inference constitutes a central untested assumption of theoretical ecology.

Preliminary attempts to estimate parameter values, and hence match model predictions against the dynamical behaviour of real ecological systems have been made amongst others, by Beddington, Free and Lawton [2], Gilpin and Justice [15], Levin, Stewart and Chao [23] and Gurney and Nisbet [17]. Such exercises are essential if theoretical models are to have the correct structure, and lie within biologically sensible parameter domains.

Despite its fragile experimental base, the assumption that persistent natural ecological communities must have model counterparts that are locally stable has lead to a number of insights.

Of particular relevance to the questions which we 
posed at the outset is the relationship between species diversity and stability in ecosystems. The ecological literature is permeated with the general notion that more diverse ecological systems are more stable [60]. At worst neither word is defined ; at best the empirical evidence is contradictory and only poorly related to theory [40]. Here we trace the main theoretical arguments.

The seminal papers are those of May $[29,30]$ on the stability of randomly constructed food-webs described by deterministic differential equations of generalized Lotka-Volterra form. For such random webs, the probability that the system will be locally stable decreases as the number of species in the web increases, as connections between species (connectance) increases, and as interaction strengths increase. Despite this constraint, countless highly complex ecosystems persist in nature. If we assume that they are to be described by locally stable models (large scale cycles or repeated extinctions are not normal properties of most populations) these complex systems raise intriguing questions about the special, non-random, features of natural food-webs which overcome the general mathematical constraint that diversity begets instability.

First, we note that the introduction of even crude hierarchies into the structure of general Lotka Volterra food-webs has a markedly stabilizing influence [39]. Unfortunately, McMurtrie's model food-chains are not sufficiently realistic to tell us much about real systems. Other minor, though nonetheless interesting elaboration are provided by Roberts [51] and Yodzis [69]. The most important modifications to the model are those of Gilpin [12] and in particular De Angelis [7], both of whom point out that randomly constructed food-webs may contain biological absurdities. To be biologically sensible, model food webs must obey at least the following constraints :

i) The rate of decrease of biomass by an eaten population must always be greater than the rate of increase of the population doing the eating. The model must be recast in biomass terms to include this elementary energetics constraint.

ii) Food-webs exhibit trophic structure. Autotrophs (plants) which can exist in the absence of all other members of the webs must form the base of the food-chain ; all other populations (heterotrophs) must decline to extinction if they occur alone.

iii) Links which form closed loops (A feeds on $\underline{B}$, which feeds on $\mathrm{C}$, which in turn feeds on $\underline{A}$ ) are nonsense.

For a full discussion of these and other details see references [7] and [12].

Incorporating these constraints into models now leads, under some circumstances, to an increased probability of local stability as the system becomes more complex. To summarize briefly, these are the cases where :

i) The efficiency of conversions of prey biomass into predator biomass is low. ii) The higher trophic level species experience strong self-damping.

iii) There is a bias toward donor-dependence in the interactions.

With the exception of (i) for which there is reasonable empirical data [41], [66], it is not clear whether these constraints are met by complex natural foodwebs.

However, one other property which enhances the probability of local stability in models is certainly a feature of natural systems. That is the division of the community into a series of relatively discrete subwebs [30]. Such compartmentalization is a common feature of natural food chains [54], [61], [68].

There is no question of these general, deterministic models yielding anything but the most qualitative insights of the type outlined above. The real world is not deterministic. In a stochastic environment, the system is in tension between the stabilizing population interactions and destabilizing environmental fluctuations, and the condition for local stability in a model analogue is therefore no longer simply that the real parts of the eigenvalues of the stability matrix must be less than zero. Rather the eigenvalues must be contrasted with the magnitude of the characteristic environmental variances, and will typically be less than zero [33]. How much less is entirely unknown. In other words, in the noisy real world the fact that an interaction is locally stable in a deterministic model may be irrelevant to the problem of population persistence. There have been few attempts to go beyond this simple qualitative insight except in one context [22].

However, there are alternative approaches. As the real part of the dominant eigenvalue of the interaction matrix decreases, so do return-times, the characteristic speeds with which the system damps.

Formally :

Return time $=-1 /$ Real $\left(\hat{\lambda}_{\text {max }}\right) \quad$ (for all $\dot{\lambda}<0$ ).

We may use this result to rank the feasibility of locally stable models on the grounds that the faster the return-time, the more likely the populations are to persist in a stochastic environment [2], [24], [25]. For example it has been shown that long food chains tend to have very long return times. This may be the primary reason why communities rarely have more than four or five trophic levels. Certainly the classical argument, that food chain length is set by energetic constraints, falls down because food-chains are not noticably longer in more productive ecosystems [47].

On problem that has been noted with this whole approach is that as the order of simple Volterra system becomes high, extremely completed non equilibrium behaviour may occur [13], [38]. The problem that this would present for the analysis of biological system is considerable. However some doubts have been raised as to the likelihood of such 
behaviour persisting in nature because usually the population trajectories occur arbitarily close to the axis and thus in a randomly fluctuating environment would necessarily imply simplification of the system due to extinction. This is discussed in more detail by Coste (This meeting).

Stability analysis has not simply been used to determine whether or not a particular community is stable. Crucial to the problem of the limitations to the complexity of an ecosystem is the idea of invasibility. This notes that for a community to be more complex new species will need to enter and that this will require that growth should be possible for the invader species at low densities. Consideration of this idea has resulted in insights into the limits on niche overlap that are likely for guilds of competing species [27], [53].

Finally we note that sets of non-linear equations are capable of generating more than one locally stable equilibrium configuration [14], [37]. Such behaviour has been documented in a number of natural systems [59] and may emerge as an important general property of communities, with important implications for the management and exploitation of populations and ecosystems [19].

Our concluding remarks can be brief. Throughout this paper we have focussed on the insights that can be gained by using differential equations. However many ecological processes involve a strong periodic component determined by the seasons. In constructing mathematical models of such population processes use has been made of difference equation formulations. The dynamics of such systems are known to be bizarre [36] when non linearities are strong and it is far from clear that the results developed for differential equation models will remain in a discrete formulation. The only relevant study of large ecological systems in discrete time is that of Austin and Cook [1] and revealed large numbers of possible equilibrium configurations, coupled with the additional property of strange attractors to which the system moved in a complicated dynamic sequence.

Putting questions of the difference between discretetime and continuous-time formulations aside, perhaps the most crucial problem facing theoretical and experimental community ecology at the present time is to work out how well connected the components of real communities actually are. We have already seen that high levels of connectance in model food-webs more or less guarantee local instability or can generate a bewildering variety of multiple equilibria. Text book diagrams of real food-webs [43], [46] look complex and suggest that high connectance is the rule rather than the exception. We disagree. Most of the links shown in these diagrams are in no way density dependent or controlling. Single-species population studies (for reviews see [18], [48]) usually identify one or at most two density-dependent or delayed density dependent stages in the life-history of the study organism. All the rest of the links are substractive, but density independent. It is obvious from the models that the key links, determining the dynamics of the food-web as a whole are the density dependent ones, so that a simple diagram massively over-estimates the true connectance of the system.

One of the more interesting things about ecology is the considerable advances that have been made from a consideration of the dynamics of a single species, or pair of species, and ignoring all the rest (for a useful overview, see [35]). It looks like cheating but it also seems to work. In other words perhaps many ecological systems are very loosely connected in terms of major controlling links between species.

If this were true, it alone would largely bypass the paradox of the persistance of complex natural communities, discussed earlier. It would also have major implications for the sorts of models we would need to construct to understand very large assemblages of species.

\section{References}

[1] Aưsin, M. P. \& Cook, B. G., J. theor. Biol. 45 (1974) 43558.

[2] Beddington, J. R., Free, C. A. \& Lawton, J. H., J. Anim. Ecol. 45 (1976) $791-816$.

[3] Caswell, H., J. Theor. Biol. 34 (1972) 419-39.

[4] Caswell, H., Ecol. Monogr. 46 (1976) 327-54.

[5] CoDy, M. L., Competition and the structure of bird commur nities (Princeton Univ. Press; Princeton. N.J.) (1974).

[6] CoDy, M. L. \& Diamond, J. M., Ecology and evolution of communities (Belknap Press, Harvard University, Cambridge, Mass. London) (1975).

[7] De ANGelis, D. L., Ecol. 56 (1975) 238-43.

[8] Fargue, D., C.R. Acad. Sci. Paris B 277 (1973) $471-7$.

[9] Fuentes, E. R., Ecology 57 (1976) 3-17.

[10] Gilbert, L. E., Colloq. Int. C.N.R.S. 265, Comportement des Insectes et Milieu Trophique (1977) 399-413.

[11] Gilbert, N. \& Hughes, R. D., J. Anim. Ecol. 40 (1971) 525-4.

[12] GiLPIN, M. E., Nature 254 (1975) 137-9.

[13] Grlpin, M. E., Am. Nat. 109 (1975) 51-60.

[14] Gilpin, M. E. \& CaSE, T. J., Nature 261 (1977) 40-2.
[15] Gllpin, M. E. \& Justice, K. E., Nature 236 (1972) 273-4. [16] Gould, S. J., in Theoretical Ecology, Principles and Applications, R. M. May, editor (Blackwell Scientific Oxford) 1976, p. 218-36.

[17] Gurney, W. S. C. \& Nisbet, R. M., J. Anim. Ecol. 47 (1977) 85-102.

[18] Hassell, M. P., Lawton, J. H. \& May, R. M., J. Anim. Ecol. 45 (1976) 471-86.

[19] Holling, C. S., Ann. Rev. Ecol. Systematics 4 (1973) 1-23.

[20] K ARR, J. R., Ecol. Monogr. 46 (1976) 457-81.

[21] LAWLOR, L. R. \& SMITH, J. M., Am. Nat. 110 (1976) 79-99.

[22] LEIGH, E. G. Jr., Ecology and Evolution of Communities (1975) 5-73 (Cody, M. L. and Diamond J. M.).

[23] Levin, B. R., Siewart, F. M. \& Chao, L., Am. Nat. 111 (1977) 3-24.

[24] Levins, R., Evolution in changing environments (Princeton Univ. Press, Princeton. N.J.) (1968).

[25] Levins, R. (1970). In Waddington, C.H. (Ed) Towards a Theoretical Biology Vol. 3 (Edınburgh Univ. Press). 
[26] LoTKA, A. J., Elements of physical biology (Williams \& W11kins, Baltimore) (1925).

[27] Macarthur, R. H. \& Levins, R., Proc. Nat. Acad. Sci. US. 51 (1964) 1207-10.

[28] MacDonald, N.. Math. Biosciences 28 (1976) 321:30.

[29] May, R. M., Proc. Ecol. Soc. Australia 6 (1971) 18-56.

[30] MaY, R. M., Nature 238 (1972) 413-4.

[31] MaY, R. M., Ecol. 54 (1973) (2) 315-25.

[32] MAY, R. M., Stability and complexity in Model ecosystems (Princeton, U.P. Princeton, N.J.) (1973)

[33] MaY, R. M., Am. Nat. 107 (1973) 621-50.

[34] MAY, R. M. (Cody, M. L. \& Diamond, J. M.), Ecology and Evolution of Communities (1975) 81-120 (Harvard U.P. Cambridge Mass. \& London).

[35] MAY, R. M., Theoretical Ecology, principles and applicanons (Blackwell Scientific, Oxford) (1976).

[36] MAY, R. M., Nature 261 (1976) 459-67.

[37] MAY, R. M., Nature 269 (1977) 471-7.

[38] May, R. M. \& Leonard, W. J., SlaM J. Appl Math. 29 (1975) 243-53

[39] MCMURi RIE, R. E., J. theor. Biol. 50 (1975) 1-11.

[40] MCNaughton, S. J., Am. Nat. 111 (1977) 515-25.

[41] MCNeill, S. \& Lawton, J. H., Nature 225 (1970) 472-4.

[42] NeILL, W. E., Ecology 56 (1975) 809-26.

[43] Odum, E. P., Fundamentals of Ecology (W. B. Saunders, Philadelphia 3rd edition) (1971).

[44] Olson, D. \& Pimentel, D., Environmental Entomol. 3 (1974) $621-4$.

[45] Oster, G. \& Takahashi, Y., Ecol. Monogr. 44 (1974) 483501.

[46] Phillipson, J., Ecological Energetics (Edward Arnold, London) (1966) Institute of Biology's Studies in Biology 1.

[47] Pimm, S. L. \& Lawton, J. H., Nalure 268 (1977) 329-31.

[48] Podoler, H. \& Rogers, D., J. Anim. Ecol. 44 (1975) 85-114.

[49] PORTer, J. W., Science 186 (1974) 543-5.
[50] Price, P. W., Evolution 28 (1974) 76-84.

[51] Roberts, A., Nature 251 (1974) 607-8.

[52] Rogers, D. \& Hubbard, S. (Usher, M. B. and Williamson, M. H.), Ecological Stability (1974) 99-119 (Chapman and Hall, London).

[53] Roughgarden, J., Theor. Popul. Biol. 5 (1974) 163-86.

[54] SHURE, D. J., Ecol. Monogr. 43 (1973) 1-19.

[55] SimberLofF, D., Ecology 57 (1976) 629-48.

[56] Southwood, T. R. E., Colloq. Int. CNRS 265, Comportement des Insectes et Milieu Trophique (1977) 471-93.

[57] Stephevson, T. A. \& Stephenson, A., Life between tidemarks on rocky shores (W. H. Freeman, San Francisco) (1972).

[58] Strong, D. R. Jr., MCCoy, E. D. \& ReY, J. R., Ecology 58 (1977) $167-75$.

[59] Sutherland, J. P., Am. Nat. 108 (1974) 859-73.

[60] Van Dobben, W. H. \& Lowe-McConNell, R. H., Unifying concepts in ecology (Junk, PUDOC, Hague \& Wageningen, Netherlands) (1975).

[61] Vartey, G. C., Animal populations in relation to their food resources, British Ecol. Soc. Symposium 10 (1970) 389405 (Watson, A.).

[62] Vogel, T., Rend. Sem. Mat. Univ. Politec. Torino 21 (1961) 87-95.

[63] Volterra, V., Mem. Acad. Lincei. 2 (1926) 31-113.

[64] Walters, C. J. (In S. A. Levin). Ecosystem Analysis and Prediction (1975) 68-82, Proc. SIAM-SIMS Conference Alta, Utah (1974).

[65] Wangerski, P. J. \& Cunningham, W. J., Cold Spring Harbor Symp. Quant. Biol. 22 (1958) 329-38.

[66] Waldbauer, G. P., Adv. Insect physiol. 5 (1968) 229-288.

[67] WhitTAKeR, R. H., Diversity \& Stability in ecological systems. Brookhaven symp. Biol. 22. Brookhaven Natl. Lab. Lect. Sci. 178-198 (1969).

[68] Wiegert, R. G., Odum, E. P. \& SChNell, J. H., Ecology 48 (1967) 75-83.

[69] Yodzis, P., Nature 264 (1976) 540-1. 